\title{
Research on the Application of Vertical Greening in Urban Park Design
}

\author{
Hongqiang Chen \\ Sichuan University of Arts and Sciences, Dazhou, China \\ Email: zjingming2019@sina.com
}

How to cite this paper: Chen, H.Q. (2021) Research on the Application of Vertical Greening in Urban Park Design. Open Access Library Journal, 8: e7143.

https://doi.org/10.4236/oalib.1107143

Received: January 11, 2020

Accepted: February 2, 2021

Published: February 5, 2021

Copyright $\odot 2021$ by author(s) and Open Access Library Inc.

This work is licensed under the Creative Commons Attribution International License (CC BY 4.0).

http://creativecommons.org/licenses/by/4.0/

\section{(c) (i) Open Access}

\begin{abstract}
The purpose of the study is to explore the design form of vertical greening in urban parks, introduce the intangible cultural heritage with strong participation, excavate the cultural connotation of the city, further explore the integration concept of traditional cultural elements and vertical greening, and inherit and continue in the design of urban parks. In the early stage, this paper summarizes the classic cases of vertical greening in foreign countries, and finds out the application scheme of the integration of traditional cultural elements in the design of domestic urban parks. The method is to refine and abstract the traditional cultural elements such as intangible cultural heritage display, folk culture and pattern symbols from the clues of local traditional cultural elements, so as to coordinate the humanities and nature to create urban characteristics. The research results are based on the local actual case, the integration of vertical greening and local cultural elements, so that the modern city park can play its own cultural value, increase the cultural function of urban park greening, enhance the city brand image of Dazhou, enhance the cultural identity of citizens, and add more green space and cultural exchange places.
\end{abstract}

\section{Subject Areas}

Urban Planning

\section{Keywords}

Urban Park Design, Vertical Greening, Traditional Cultural Elements, Integration

\section{Introduction}

In recent years, vertical greening is considered as an important method to im- 
prove the urban environment, which is widely used in urban park landscape design. At present, the form of vertical greening design is relatively single, ignoring the cultural connotation of the city. Traditional cultural elements have rich humanistic connotation. The integration of the two in landscape design can increase the continuity of traditional culture in landscape design, increase the form of vertical greening, and make traditional culture deeply rooted in the hearts of the people. In recent years, although some trails have been completed one after another, there is a lack of design for people's routes, especially at the junction with the city. The green vegetation is single, the relationship between artificial space and natural space is chaotic, there is no design theme, and there is a lack of regional culture display with Dazhou characteristics. Focusing on the design of "Fenghuangshan Park", this paper adopts the design method of vertical greening and integrates the vertical greening and traditional cultural elements into the urban park, which has a positive impact on beautifying the city and enhancing the connotation of urban culture.

\section{Vertical Greening Situation and Case Analysis}

\subsection{Definition of Vertical Greening}

Vertical greening is mainly relative to plane greening, which is an effective supplement to plane greening. It belongs to a new form of greening, which refers to a way to beautify the environment by using all kinds of plants. The greening forms on building walls, slopes, roofs, courtyards, flower racks, scaffolding, river embankments, pavilions, fences, green sculptures and building facilities all belong to the vertical greening. Focus on the limited space environment, the use of plant growth and development mode, select the appropriate plant planting, cover in the roof, balcony or wall surface greening form [1].

As one of the important forms of urban greening development, vertical greening plays an important role in improving the urban living environment, enriching the visual landscape and displaying urban cultural connotation; The development of vertical greening can enrich the spatial structure level of urban landscaping, show the artistic effect of urban three-dimensional landscape, and further increase the urban green quantity, reduce noise and dust, and reduce the heat island effect and harmful gases, so as to achieve the purpose of improving the urban ecological environment.

Dazhou urban greening construction started late, and there is still a big gap with the provincial capital and coastal cities. For example, the total area of greening is not large, the distribution of greening is uneven, the characteristics are not distinct, the collocation of trees, shrubs, grass and flowers is not reasonable, there are not many local cultural elements integrated into the urban parks, and the landscape lacks the focus of characteristics. By the end of 2018, Dazhou city has been covered by forests. The rate of green space per capita reached $43.51 \%$, and the park green space per capita reached 9.78 square meters. Although the work of creating Forest Park has achieved phased results, the per ca- 
pita green space is less than 10 square meters, compared with the best living environment standard, there is a big gap [2].

\subsection{Classic Cases of Vertical Greening in Urban Park Design}

With the development of social economy, the traditional greening mode has been unable to meet the ecological and social needs of urban parks. Vertical greening can play a more and more important role in urban greening. In Milan, known as the "fashion capital", there are two world-famous "vertical forests". These two buildings were designed and built by Stefano Boeri. The buildings are composed of folk houses and plants. A total of 730 trees, 5000 shrubs and 11,000 herbs are planted on the outer wall layer by layer. The vertical greening takes up less land, makes full use of space, greatly improves the amount and coverage of urban green, and enhances the three-dimensional effect of green. By beautifying the bare walls and soil slopes, the environmental quality is improved. As the climbing plants change with the appearance of objects, the rigid outline of buildings is softened and integrated with urban greening, which will create a variety of vivid decorations Effect: through the transpiration and shading effect of plant leaves, the direct sunlight on buildings can be alleviated, and the wall temperature in summer can be greatly reduced [3].

Relevant data shows that when exposed to the sun, the temperature of the green covered wall is 13 - 15 degrees lower than that of the non covered wall. After falling leaves in winter, it does not affect the wall to get the solar radiation heat, and its branches and stems attached to the wall become a layer of insulation layer, which plays a role in regulating the indoor temperature. The three-dimensional greening of building facades can absorb smoke and dust to a certain extent. This project also aims to purify the air in the city. These trees will help to increase humidity, absorb carbon dioxide and dust particles, and produce oxygen, which will greatly improve the quality of life of residents and create a natural barrier against radiation and noise [4].

\section{Application of Vertical Greening in Urban Park Design}

\subsection{Design Background}

The park along Fenghuang Mountain is the city park of Dazhou City, with beautiful scenery and high green coverage. It has a unique landscape and cultural characteristics, with an altitude of nearly 800 meters. It is located in the center of the city, and can overlook the whole city from the top. It's beautiful in shape, just like a "phoenix" with wings. It has strong cultural connotation. It is the main place to carry the Dacheng intangible cultural heritage "annual Climbing Festival". It has green trees and fresh air. There are "Red Army Pavilion", "Yuanzhen Memorial Hall", "Han que" and "moon worship platform" and other scenic spots. Along the way, you can enjoy the strong red army culture, Buddhist culture and Yuanzhen culture. Han culture and folk culture are good places for people in Dacheng to enjoy leisure, climbing, sightseeing and folk customs. 
The scenic spots of Fenghuang Mountain Park are mostly concentrated on the upper part of the mountain. Although some of the trails around the mountain have been completed in recent years, there is a lack of design around the line which is more accessible to people, especially the design of the junction with the urban living area. The planning and design are not clear, and the green vegetation is single, resulting in a great waste of land resources; the relationship between artificial space and natural space is chaotic, and there is no form. There are some potential safety hazards; lack of relatively complete supporting facilities, theme amusement and not much consideration for all ages, insufficient excavation and display of folk culture with Dazhou characteristics; There are many peddler activities on the mountain. Park management is inconvenient, resulting in environmental pollution. How to provide a Dazhou characteristic mountain park with entertainment, leisure and culture for citizens, which is conducive to the sustainable development of the city and becomes the "green lung" center of the city, is the premise of project design.

\subsection{Design Concept}

The park design along Fenghuang Mountain in Dazhou city takes the traditional cultural elements of Dazhou city as the design materials, integrates the traditional cultural elements into the urban park design, and endows the traditional cultural elements with new connotation. Through the three-dimensional greening design, people can understand the local folk culture of Dazhou City, popularize the knowledge of ecological design, create a considerable green environment, and integrate the traditional cultural connotation with modern design. The combination of techniques shows the inheritance and renewal of urban landscape.

Using the cultural elements of "stone bridge fire dragon" in Dachuan District, the paper creates a three-dimensional green carving of "double dragons playing in the water". As a landscape node, it abstracts the undulating shape of the fire dragon dancing, combines with the functions of rest, viewing, entertainment, etc., and forms a three-dimensional dancing green plant. By studying the characteristics of "Han Que" in Quxian County, such as stable and simple style, concise and exquisite carving, vivid and elegant modeling, it extracts its text with different color attributes of plants, the theme of "hanque square" is created. The three-dimensional greening creates landscape nodes, which not only have beauty, but also carries profound cultural connotation. According to the needs of Fenghuang Mountain, the design is naturally integrated with the original site, and the humanistic connotation is integrated into the three-dimensional green landscape. The application of traditional elements makes the primary and secondary of the whole scenic area orderly and coherent. The simple and generous Chinese architecture adapts to local conditions follows the needs of Fenghuang Mountain, and the design is naturally integrated with the original mountain form. The humanistic connotation is integrated into the natural landscape, so that the whole garden has a beautiful environment, pleasant scenery, rich con- 
notation and excellent taste, so that visitors can really enter a splendid historical and cultural treasure house.

The park design along Fenghuang Mountain in Dazhou city combines "traditional culture" with the vertical greening to set off the atmosphere of urban park with the breath of traditional culture, to display the city's traditional artistic achievements and cultural heritage, and to provide cultural exchange places for citizens, which helps to enhance the sense of cultural pride and urban spiritual character; The vertical greening adds a new touch of green to the city, making the city more prosperous. Traditional cultural elements and the vertical greening concepts are inherited and continued in landscape works, which improves the cultural atmosphere of the site and updates the concept and connotation of park design.

\subsection{Design Principles}

The design of the park along Fenghuang Mountain in Dazhou city is in line with the practical aesthetic principle of landscape. According to the aesthetic requirements of the public, the beautiful, comfortable and healthy landscape environment is designed. The vertical greening design of the park road and adjacent to other urban space helps to improve the urban environment, purify the air, block all kinds of suspended dust harmful to the human body in the air, and improve the thermal stability Island effect, cooling, noise reduction; The construction of landscape belt on both sides of the river, cultivating waterfront green corridor, so that people can see the green when they open the door and walk in the vertical greening; The design of footpath leisure area in the middle reaches of the park, paying attention to the green plant design of corridor and the creation of lawn micro landscape, to meet people's aesthetic needs, but also bring tourists a three-dimensional landscape experience. The park presents the natural landscape effect of changing seasons, lush grass, lush grass, warblers singing and green mountains and waters, which makes visitors forget to return.

The vertical greening of urban parks follows the overall design principle. The landscape design of parks along Fenghuang Mountain in Dazhou City, based on the principle of harmony between humanity and nature, highlights the urban characteristics and constructs the characteristics of the vertical greening landscape. It not only shows the mountains and waters, respects nature, but also relies on the culture of hate and bashantang canal to introduce the non-material cultural heritage with strong participation and tap the potential of the city. Through the effective protection and rational use of these original ecological, natural and cultural landscape resources, we can build characteristic garden landscapes and enhance the city brand image of Dazhou.

The integration of the vertical greening design into urban parks improves the greening rate, enhances the carrying capacity of the ecological environment, and adheres to the green concept of sustainable development, which is in line with the principle of ecological design. The design of the Park focuses on the viewing 
platform, rocks and waterfalls, leisure facilities, activity center and entrance landscape of the park, creating green trees and natural landscape, integrating public leisure, family farm, community science and education experience and other functions, giving more sustainability to urban space, meeting the pastoral ideal of some urban people, enriching the three-dimensional level of greening, and improving the landscape effect, Increase the space for people to communicate, let the children experience the practical education personally, create a pleasant ecological space environment while the public can participate, and also make the landscape productive [5].

\section{Vertical Greening in Dazhou Fenghuangshan Park}

\subsection{Landscape Design of "Dragon Playing in Water"}

In the design of Fenghuangshan Park, the vertical greening mainly reflects the waterside promenade on the island in the middle of the lake, with fresh air and layers of green hills. The design of "dragon playing with water" vertical greening landscape is the focus of the theme park design (Figure 1). The spectacular vertical greening of "dragon playing with water" symbolizes good weather. The design of green carving in the cultural functional area arranges the vertical greening landscape of "dragon playing with water". The "dragon" has a unique significance in Shiqiao Town of Dazhou city. People pray for a bumper harvest in the coming year through a series of folk activities of stone bridge fire dragon in the new year. The "fire dragon" carries Dazhou people's desire for a better life, and is also a symbol. It represents the good expectation of the farmers [6]. Through the collection of fire dragon elements in Shiqiao, the structure of "dragon" is refined, and its posture is expressed in the form of vertical greening. The vertical greening and traditional cultural elements are skillfully integrated. The two "Dragons" in the center of the lake are completed by vertical greening. They play in the water and are full of fun, creating an ecological environment with a sense of culture, giving Phoenix Mountain Park new vitality, at the same time, it can

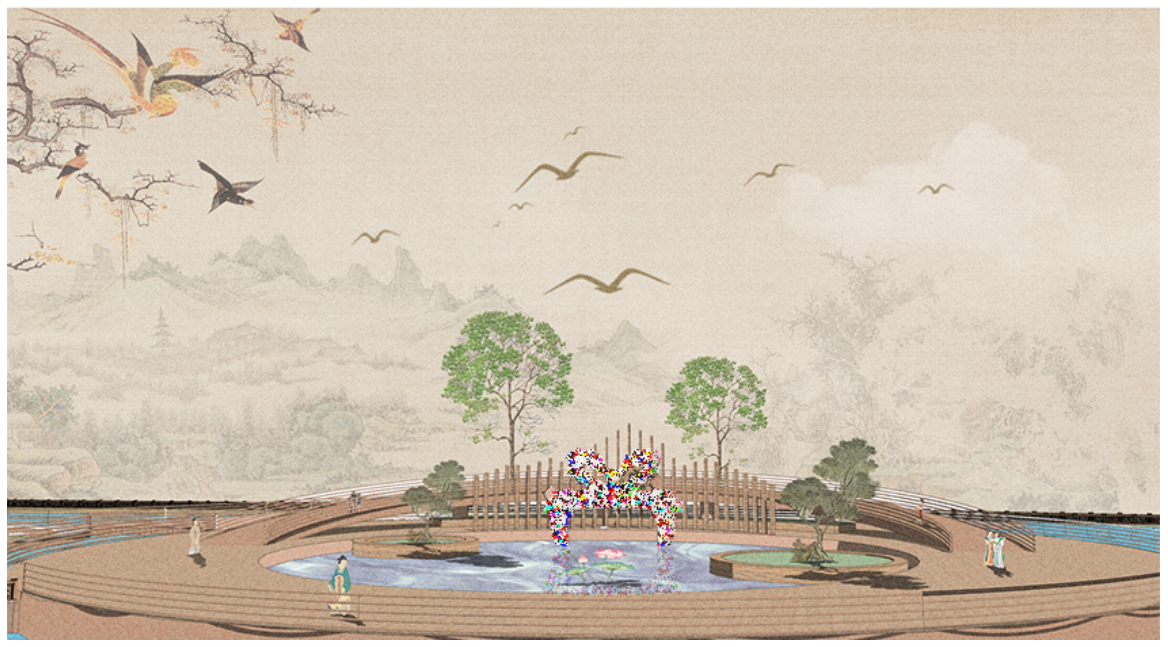

Figure 1. Dragon playing with water. 
also meet the spiritual needs of tourists and promote and continue the traditional culture [7].

\subsection{Greening Design of "Hanque Square"}

In the design of urban park, sculpture, as an important visual element, is displayed in the form of vertical greening to highlight its visual center. Just like the point in the composition, it highlights the characteristics and design theme of the park from the point of view. The design of "hanque square" is the soul of the whole park. Under the background of "hanque" culture, the story of father and son behind "fenghuanque" reflects the concept of loyalty and filial piety in Han Dynasty, and carries forward its positive filial piety culture, which is an important source to show the city spirit. The design of hanque square does not adopt the traditional "Shique" construction, but presents it in the form of vertical greening "green carving" (Figure 2). Whether from the selection of plants, color matching, or cultural construction, it is a new vertical greening design method, creating a three-dimensional cultural atmosphere with green everywhere and green characteristics [8].

The three-dimensional green sculpture of "hanque square" has coordinated plant colors, the volume of the sculpture and the surrounding environment complement each other, and the new vertical greening design concept is used for landscaping to highlight the characteristics of urban culture. The highlight of the design lies in the planning of the park, which respects the natural ecological environment, natural terrain, landform and other natural ecological conditions. Through the water body planning and reasonable plant configuration, it creates a vertical green space in the park, and divides the scope of the square, solves the relationship between art display and display, and integrates the cultural landscape into the public space Garden design [9].

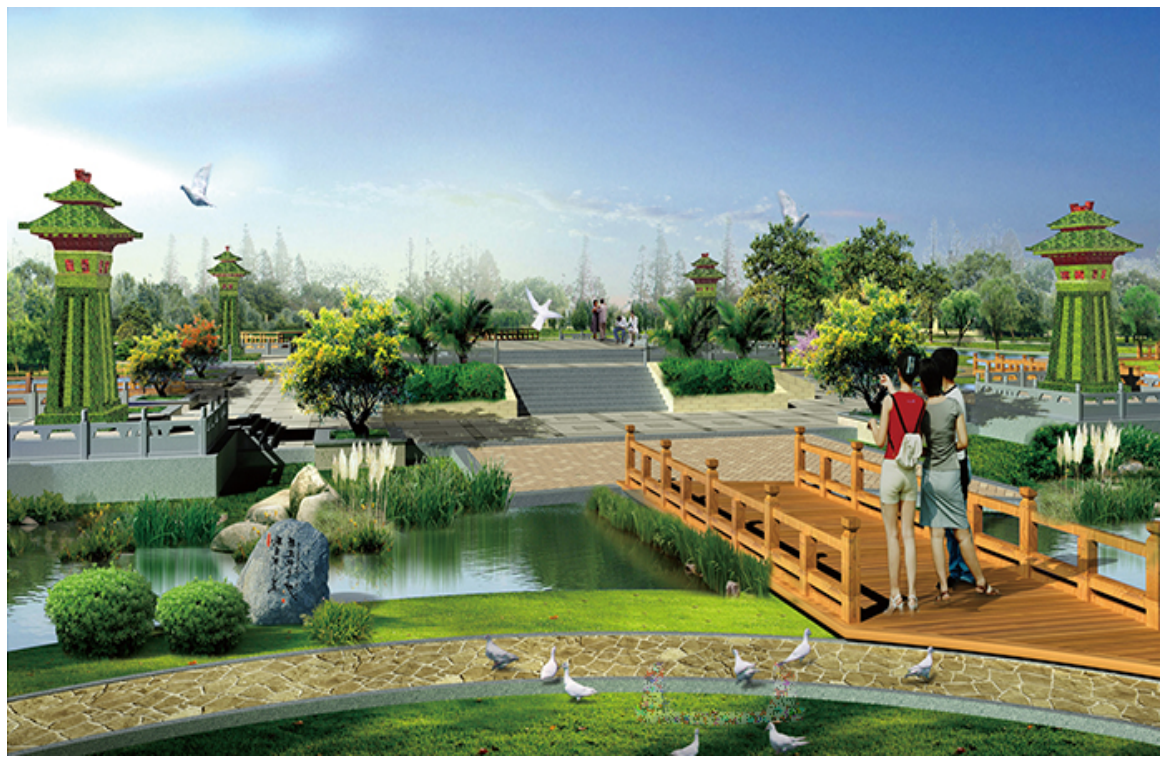

Figure 2. Greening design of "hanque square". 


\subsection{Design of Flower Bed in Entrance Area}

Through the decoration design of plants, through the color matching among plants, a living green sculpture is formed. Using the principle of color aesthetics, the decoration function of plants is extended from the plane to the three-dimensional space [10]. The three-dimensional flower bed in the entrance area of the park is composed of a variety of flowers and plants with different colors. The flower design combined with three-dimensional greening reflects the three-dimensional landscape and color of the park. The colorful entrance three-dimensional flower bed fully meets the aesthetic needs of tourists. Combined with the characteristic "bamboo" sculpture, it gives people a bright feeling. The three-dimensional flower bed forms a three-dimensional decorative effect, enriches the level of space greening, enriches the environmental atmosphere, and effectively shapes and improves the image of the park.

\subsection{Greening Design of Leisure Area}

The whole northeast area of the park is a leisure and sightseeing area. People visit and walk in the picturesque scenery, feel the green brought by nature, breathe the fresh air, embrace nature, and feel the strong traditional cultural atmosphere. Vertical greening is mainly reflected in the architectural design, using climbing plants to grow freely on the column edge of the building, making it a flower Gallery, green Pavilion, and bookcase French characters become a scene of the park. Based on plant landscaping, we should create a kind of humanistic landscape which is based on mountains and rivers, and human and nature coexist. We should combine the three-dimensional greening landscape with the landscape of mountains and rocks, and create a combination of green carving and dragon playing in the water. In the elegant waterside corridor, we can feel the landscape node of "dragon playing in the water", which has a unique cultural interest.

\section{Conclusion}

In the design of Fenghuangshan Park in Dazhou, vertical greening effectively promotes the green development of the city. Through the planning and layout of vertical greening landscape, it creates a unique cultural atmosphere. Combined with the ecological design principle of vertical greening design, it meets the aesthetic, leisure, learning, memorial and other needs of tourists. Through the reasonable allocation of plants, it creates a unique green sculpture to create a beautiful landscape. The sense of place cultural belonging endows the spiritual function of green landscape, expands a broader and more design sense of urban green space, and develops the practice case of vertical greening design of urban park. The article also lacks the corresponding technical analysis of vertical greening, the lack of targeted research on plant conservation, and more detailed research on policy research and residents' understanding. The follow-up study should increase the systematic research of relevant subject knowledge, so as to 
provide a reference scheme for the vertical greening design of urban parks.

\section{Conflicts of Interest}

The author declares no conflicts of interest regarding the publication of this paper.

\section{References}

[1] Zhang, W. and Zhang, J. (2010) Current Situation and Countermeasures of Urban Three-Dimensional Greening Construction in Shijiazhuang. Journal of Hebei University of Economics and Trade, No. 1, 91-93.

[2] Li, Y. (2015) Vertical Greening: A New Favorite of Greening and Renewal in Historical Cities. Guidance of Building Materials Development, No. 1, 63.

[3] Wang, J. and Chen, X. (2016) Design Principles and Plant Configuration of Urban Vertical Greening. Architectural Engineering Technology and Design, No. 15, 35-35.

[4] Guo, X.Y. (2011) Vigorously Developing Vertical Greening in Mountainous Cities. Theoretical Research on Urban Construction, No. 31, 28.

[5] Zhang, B.X. (2003) Three Dimensional Urban Greening. China Forestry Press, Beijing.

[6] Meng, G. (2003) Urban Park Design. Tongji University Press, Shanghai.

[7] Shi, J.X. (2017) Landscape Design of Urban Cultural Theme Park. Architectural Engineering Technology and Design, No. 20, 90.

[8] Liu, D. (2017) Research on the Application of "Vertical Greening" Design in the City: Chongqing as an Example. Chongqing University, Chongqing.

[9] Ma, X. (2018) Landscape Design of Urban Cultural Theme Park. Farmhouse Science and Technology (Next Issue), No. 3, 1.

[10] Shang, Y.W. (2014) Application and Development Prospect of Three Dimensional Flower Decoration. China Packaging Industry, No. 4, 87. 